\title{
Repair, Rebirth and Recreation in Urban Renewal
}

\author{
Qingxi Fan \\ School of Packaging Design and Art \\ Hunan University of Technologe \\ Zhuzhou, Hunan, China
}

\begin{abstract}
Repair and renovation of old buildings is an effective approach to promote the urban renewal. Recreation of urban special situations is a high-level respect to urban context. Using the case analysis method, this paper analyzes representative examples of urban renewal in Hong Kong and Taiwan to discuss the necessity to combine renovation of the old buildings with regional natural environment, cultural and historical environment and compliance with spirit of place.
\end{abstract}

Keywords-urban renewal; old buildings; reactivation; special situation; recreation

\section{INTRODUCTION}

In 1950s, due to people's disappointment to disappearance of traditional urban fabric and historical context under the concept of modernist planning, Britain was buzzing with historical protection activities. In 1953, issuance of Historical Buildings and Monuments Protection Act led to people's awareness of the fact that the urban building cluster, external space, roads, squares, etc, constituted an indivisible organism and overall historic scenery areas should be more vigorously protected than a single building. Historical buildings which are passed from generations to generations are carriers of historical information and also reflections of traditional cultural value... Thus, destroy of those areas will lead to cultural, social and even economic losses. China's urban renewal has been transferred from conservativeness and inflexibility to pursuing new. We can't stand desolation of natural environment, but allow the precious human environment damaged. "Organic renewal" concept was proposed and gradually improved by the professor $\mathrm{Wu}$ Liangyong in the course of old city renovation in Beijing. He advocated making a difference in dealing with residential buildings according to the current state of houses. He believed that buildings with good quality and value of cultural relics should be reserved, buildings part of which was in good conditions should be repaired and crumbling buildings should be removed and renewed. Just as the organism, the city should be organic, interrelated and of harmonious coexistence from whole to local. Each component of the city is metabolized continuously and must comply with original urban structure. Such process of metabolism should be gradual and continuous and comply with internal order and regularity.

\section{REPAIR AND RECREATION OF OLD BUILDINGS}

Some ruins are deliberately permanently preserved. Although they materially belong to remains of buildings, in fact they are detached from the ruins what are actually stated and become the eternal relics. Although some so-called "antique buildings" have the features of traditional buildings and actually have the architectural symbols of traditional buildings and folklore custom, it's difficult for them to achieve the goal of manifesting the cultural context. Thus, both the ruins deliberately made and the ancient towns constructed everywhere in the name of development actually belong to lifeless arthrofacts. "Life" is unable to last and "cultural context" is unable to be created. Thus, trying best to repair and "renew" the old buildings is a reasonable respect to them.

\section{A. Urben Renewal Project of Taipei}

Since the end of last century, the concept of "reutilization of vacant space" has become new idea and policy direction of cultural heritage protection in countries. Following this concept, Taipei proposes the "urban renewal planning", among which historical and cultural areas are required to be maintained and preserved. During the implementation of planning, "field domain" concept has been introduced, which means that the protection of cultural heritage is expanded from single buildings to the connection between the architecture and the environment and residents' life.

Dihua Street has always been an important hub of Taipei for grocery, tea and Chinese medicinal materials and fabrics. Most of stores have long-strip shape and are multi-span. Although those stores are not wide in the front, they are quiet long and deep and combined with commercial and residential functions, which is a typical form of Taiwan Street in the Qing Dynasty "Fig. 1". As far as the eye can see, the whole street is filled with different styles of buildings, such as modernistic style, baroque, western-style, southern Fujian style, etc. Although implementation of "urban renewal" planning also experienced the dispute over retention or abolition in the last $1980 \mathrm{~s}$, the original $7.8 \mathrm{~m}$ wide style for the street was finally kept. In the street, there are 77 buildings which are mixed with the buildings with southern Fujian style in Qing Dynasty and the buildings rebuilt during the period of Japanese occupation. In 1996, after renovation and repositioning of "Chinese New Year Shopping", the old street with a length of about 800 meters came back to life. 


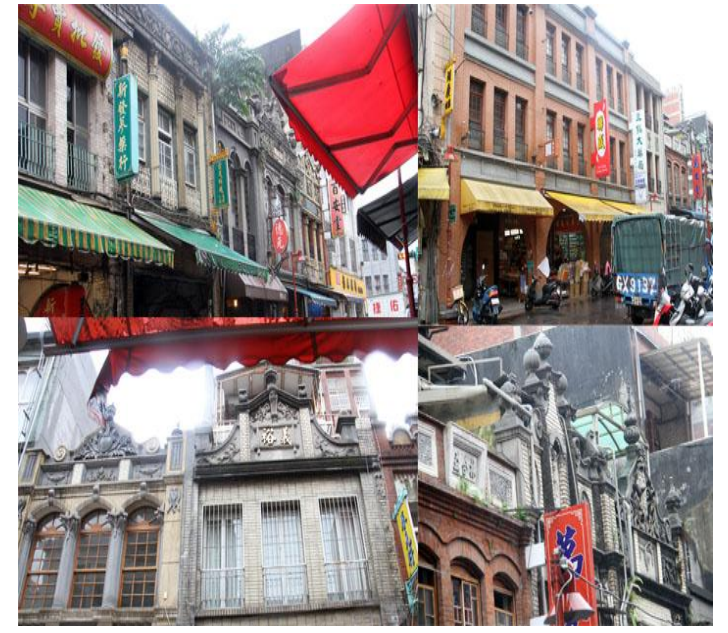

Fig. 1. Taipei Dihua Street

Compared with Dihua Street, rebirth of "Yushan Hotel" is a spontaneous behavior of the public. This building which has a glorious history due to industrial railways in Japanese colonial period, was in the risk of closing business since forestry policy shift in 1960s. In order to protect Yushan Hotel which is closely linked with the local history and culture, Yuguoxin, chairman of Hoanya Culture Association and owner of Hoanya Library leased the hotel and tried to recover its original appearance by means of archaeology of buildings and retain the accommodation function. Only in this way, the spirit of the hotel can be truly inherited. He invited many friends to repair the hotel, which moved the local people. The repair planning has gradually received the attention from many people, including the students and the net friends, who successively made efforts to renew the deserted hotel. Walking into the arcade - style building, the joggling traditional technique inadvertently added a peace of mind. Not too much decoration but simple emotion occupies each corner. There are various commodities around the wooden ladder, some of which are books from Jiayi and some are related to handicrafts and organic rice. Slogan stickers around the bar express the full care of the owner to the society. Coffee of cafe coffee on the first floor is also introduced from local farmers, with the profits directly fed back to the farmers."Yushan Hotel", which is changed as backpackers' hostel is also a small arts center, and organizes cultural activities and the market from time to time. On every Friday night, there are documentary and free films. On the last Saturday night of each month, a music lovers exchange is held and there will be one day in each week to share local handicrafts and so on.

The old wooden hotel which experiences 60 years of vicissitudes was reborn. It seems low-key but luxury actually, because it gorgeously carries stories for more than half a century. It, just like a treasure box which is slowly opened, can be touched by hands, read by eyes, and affected by hearts. It grows as we grow. Perhaps, many people may think that the old houses are not convenient, uncomfortable and unsightly, but absolutely convenient and comfortable. It is the paradox.
The currently "new" thing will eventually become the "old" thing in the future. New buildings processed by machinery operations are full of smell of concrete, but after the old house which has been transformed can still see traces of man, life, and the past. The design engineering methods, which are difficultly seen today, such as mosaic pattern, artificial carved moldings, lines of window's face, etc., are the unparalleled values.

\section{B. "Revitalization of Buildings" in Hong Kong}

In 2007, Hong Kong administrative report proposed the "progressive development", which stated that the development must also be accompanied by protection of the cultural relics and proposed to revitalization of historic buildings. In 2009, the administrative report put forward the "central conservation" program, which included: land for central piers, central market, original site of central school, central police station group, central government offices, etc. Chen Zhisi, Chairman of the Advisory Committee on Revitalization of Historic Buildings, said that conservation was not only to retain the buildings on the surface, but more importantly, to do something after retention of the buildings. The purpose of conservation is to enable generations to be aware of the historical significance of a building. Therefore, the conservation does not just mean simply retention of the buildings, but injection of new life into the buildings, which is the so-called revitalization "Fig. 2".

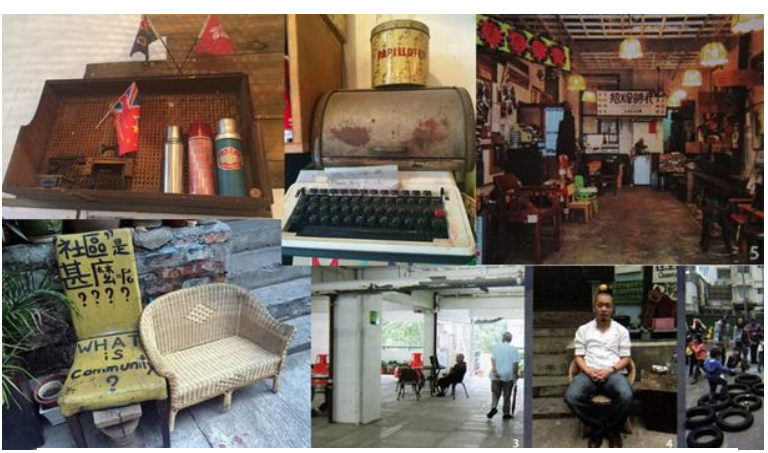

Fig. 2. Hongkong Storyeum

In some urban renewal project, the Urban Renewal Authority separated the space for the arts and cultural purposes. For example, it decided to adopt the "arts community" mode of operation to activate "Blue House" in Wan Chai, which was changed to "animation base." Hong Kong Story House, also known as "Blue House," is the result of bottom-up consultation. Since 2012, Hong Kong Story House has been committed to promoting arts culture of the community, and regularly hosting exhibitions and other cultural activities, which enabled participants to recognize folk history and culture of the entire Wan Chai, even of the entire Hong Kong. Curator Lu Yueqian is a local artist. In his view, the Story House is the platform which is used to present ideas of the neighborhood, and his role is to act as a bridge to connect the neighborhood with the House. By pursuing a bottom-up mode of operation, he often calls neighborhood meeting to discuss matters related to the 
House, with participants including residents of Blue House, nearby residents, people outside the region, as well as users of different backgrounds. All users are equal, and work together to ponder what the community is. All users are equal, and work together to ponder what the community is. An old chair outside the House impressively writes the words "what is the community?" Perhaps, this issue should be thought and felt. Exhibitions in the House are often related to image of the community. For example, Ouyang Naizhan's painting exhibition can enable the visitors to think the reason that Hong Kong is recorded by means of painting and the importance of those paintings on Hong Kong. Exhibition of "times of signboard" hopes to see changes in social values. "The older people feel the store is their lifetime of efforts, and the store is called as Chan Kwong Kee, the quality of which is guaranteed with their names.

Perhaps, as for an abandoned place or building, it's common that the place or building is always slightly repaired by the surrounding residents and used for other purposes. According to their preferences, people may "maintain" or "integrate" the old buildings. However, regardless of "maintenance" or "integration", what is important is that people always conduct the so-called improvisation by their own means.

\section{RECREATION OF SPECIFIC URBAN SITUATIONS}

Purely physical state protection of buildings usually makes the historical landscape leave external and empty form, and lack of rich flavor of life and emotional association. Thus, it's difficult to continue "life" of the building from the true sense. Urban landscape reconstruction is designed to fully tap the unique charm of historical events, the spirit of the times and cultural activities which are hidden in these historical landscapes. However, reconstruction of special situations is also selective. It does not mean that the new buildings have blindly to accommodate the style of old architecture, which will impede development of the city and the history.

In addition to being a habitat, the building also has the function as a component of the city and as a historical marker. Thus, buildings at each era should reflect the true characteristics of the times, so as to make the trajectory of the city straightforward. In the old cities which experience a long process of development, buildings at different times and with different styles gather together to show time and space span and cultural diversity.

\section{A. Taiwan's "Beitou Hot Spring Museum"- Time and Space Crisscross of Beitou History}

Hot spring culture of Beitou is inherited from warm springs of Beitou and is very suitable for showering outdoors. Since the beginning of the 20th century, under the organization of "Taiwan Women Charity Society", "charity bath" was set up here in 1907, which was the first generation of public baths. In 1913, the bath became the largest hot spring public bath in the East Asia under the planning of Jincun Daji, head of Taipei, which was the second generation of public baths (currently Beitou Hot Spring Museum). After
World War II, Beitou Hot Spring was gradually left and abandoned after evolution of time and space. Until 1994, teachers and students of Beitou Elementary School excavated this deserted bath due to rural teaching, and prepared a petition to plead for this bath. Under the impetus of other enthusiastic people, Beitou Hot Spring was announced as the third-class relices in 1997, and "Beitou Hot Springs Museum" was set up in 1998 after repair and reuse of ancient relics.

As the historic site saved and preserved by community residents, the Beitou Hot Spring Museum played the role of spirit symbol for the Beitou culture "Fig. 3". With the rise of Beitou hot spring that year, Japan geishas were introduced, and special cultures such as "Nakasi" singing while walking 1 , motor prompt delivery 2 and restaurant food 3 were derived then. In recent years, the Hot Spring Museum has actively promoted the Taiwan Moon Guitar and ballads connected with Taiwan, which has become the characteristic cultural event in the spring of Beitou.

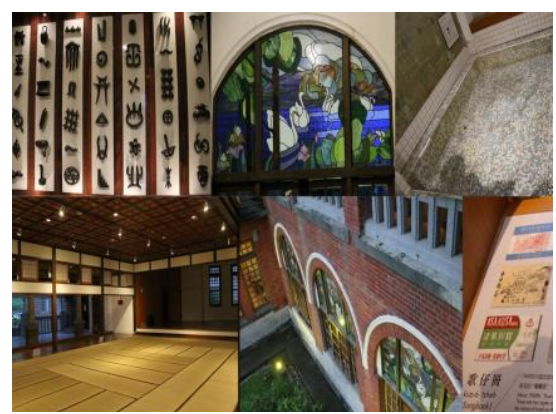

Fig. 3. Beitou Hot Spring Museum (Source: taken and organized by the author)

In May 2015, with the organization of the ADCS conference party, the author was honored to visit the Beitou

\footnotetext{
1 "Nakasi" in Japan means the walking-singer like water flowing, singing in various inns and hotels. Then Japanese going to the Beitou for bathing introduced the Nakasi. And there were more than 100 Nakasi orchestras in the hot spring area during the period of great prosperity.

${ }^{2}$ The hot spring industry in the Japanese occupation era was developed, geishas and waitresses performing in hot spring hotels and restaurants were picked up by blackhead cars and tricycles, driving in the new Beitou. With motors, special trade girls then changed to take motors to provide services more quickly, which was called "prompt delivery" therefore. In 1979, after the "abolition of prostitution" by the government, motors turned to serve general residents in Beitou, adopting the shift-arrangement system and phone booking. In the old Beitou market, there were many motor service stations in places such as along the Guangming Road, Beitou Park and intersection of Yongxing.

${ }^{3}$ Restaurants during the Japanese occupation era mainly gathered in Dadaocheng and Mengjia, but were not popular in Beitou. In 1913, it started to provide the application permissions for restaurants, and several ones of them started the operation with the price much lower than that in Dadaocheng and Mengjia. In 1930s and 1940s, many restaurants emerged in Beitou providing feast and Taiwan food, with the combination of hot spring and food. Nuskin Huifang has proposed the promotion of "year-end parties". For bookers, geisha performance and hot spring bathing are for free. And the restaurants then emerged with the market, and Beitou becomed the so-called "Food Street" and started to develop the "restaurant food" priced by tables with exquisite cooking, good appearance and ostentation as well as expensive price.
} 
Hot Spring Museum. The museum is a two-story building with the first floor made of bricks and the second floor made of woods. And the key feature of "mixing with foreign properties" is adopted for the appearance. The ceramic hot springs catheter collected in the museum is the pottery pipe designed by elders of hot spring shareholders, specially fired by Yingge Kiln and can meet demands of hot spring water after the Japanese withdrawing from Taiwan. The water storage tank connected by the pottery pipe, however, for the first time took the $\mathrm{RC}$ reinforced concrete as the outer wall and fiberglass for the façade, which addressed the matters of typhoon and earthquakes in Taiwan by adjusting measures to local conditions. When listening to the introduction in the Tatami Hall, words of Consultant Lin presented the mission of the Museum, "visitors are all playing here without the Museum; with the Museum built, visitors are experiencing the hot spring here. Except for visitors, merchants of the hot spring hotels then are guided to develop the local culture industry by relying on the community culture. Of course, all of these are attributed to the petition of children."

Moreover, the achievement of reuse for the historic site of public hot spring bath in Beitou encouraged the community residents in Beitou to further propose the concept of "creating the community by ourselves". They collected opinions from scholars, literature and history associations, principals, teachers and people from all circles of life such as the hot spring industry, so as to develop the features of Beitou culture and display the historical outlook of Beitou. And it is also the precedent one that presents both the community history and industry culture by Taipei City.

\section{B. Railway-culture Art Village in Taiwan-Railway Aesthetics of Unused Space}

In the summer of 1997, when conducting the unused space research and planning for the central region, the Department of Architecture of the Taiwan Tunghai University found out the potential value of Taiwan railway warehouse. The high and spacious interior space was very suitable for the artistic creation and display. And all warehouses along the railway can be developed and connected as an art network of features so as to display cultural features of regions through the running railway for people. Therefore, some old platforms, old railways and railway warehouses completely preserved become the "railway art villages". In June 2000, the "No. 20 Warehouse" along the Taichung Station was open for the public as the first railway art village in Taiwan. In villages, there are not only rails of old stations, but also the Guanghua compartments nicknamed with the East Line-tinker Bell (due to the color of blue-white). The compartments are re-painted with yellow-white, which were stopped for operation; however, we can still feel the atmosphere of running along the east line. In the park, there are water supply towers built during the Japanese occupation era, air-raid shelters during the World War II period, equipment rooms for the old railway station with the history of more than 80 years...All the rich railway relics restore the previous railway landscapes.
The log waiting chairs and the ground in the station house of original Fangliao Station are inlaid with artistic ceramic tiles. And many 3D ceramic plate paintings showing the landscape of Fangliao were hanged along two sides of exits of underpass, which is closely connected with the F3 Art District transformed by the old railway dormitories "Fig. 4". Here there is a scene different from the cities with be crowded with people and vehicles. Except for luxuriant trees, there are many artistic devices as well. Some are related to the rail culture, such as train icons made of flood wood and metals, as well as some Mosaic porcelain stickers, mailboxes in the shape of animals, etc.

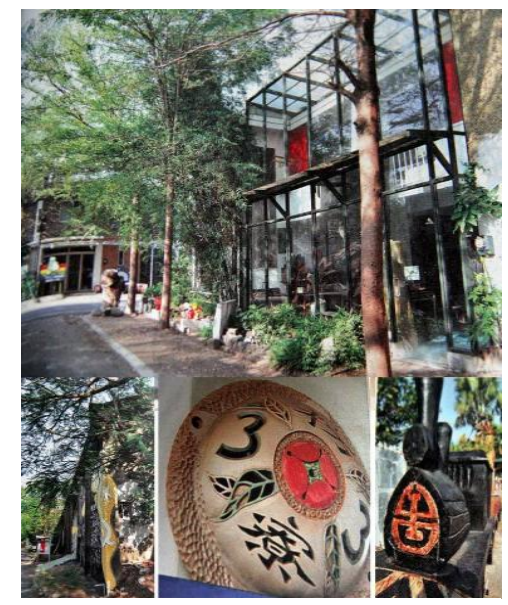

Fig. 4. F3 Art District

The Taiwan railway art villages are the good reuse of unused space, also the life aesthetics created by Taiwan cultural and creative industries. Here we attract literary and artistic groups or individual artists for creation for free. For different creation projects, the tenancy term is around half a year. And then other artists are allowed to the park for creation. With the frequent "exchange blood transfusion", it can not only ensure the constant change and innovation of the park, but also benefit each artist equitably. During the residency of artists in villages, they interact with community residents and visitors along the railway line, which promotes the innovation and promotion of the local cultural industry. Moreover, it is true that many local people may not understand the culture of his place. Once participating in courses of research, DIY, etc. in these villages, they all can then become the vital force for cultural innovation. Residents, by the independent participation, can form his own living environment to improve the building landscape along the rail corridor and create the new railway aesthetics.

\section{CONCLUSION}

Each city has its own valuable regional culture, which can be reflected by the life of residents and buildings that people rely on for living. Maybe we have not realized that these buildings have integrated with many emotions and memories for the past of ours. When one day, they are destroyed piece by piece and the original life contexts are cut 
off little by little, with certain strange and slightly aggressive culture planted. Then what we have lost is just a building.

\section{REFERENCES}

[1] Li Gang. Regional Urban Design [M]. Shenyang: Northeastern University Press. 2012: 165.

[2] TRAVELER Luxe. Slow Journey of Mysteries of Taiwan Railway [M]. Taipei: Moke Publications Limited, February 2015.

[3] Pace of Government Policy-Exclusive Interview for Home Affairs Bureau, Urban Reconstruction Authority \& Activation of Historical Building Advisory Committee [J]. Art plus. HONGKONG • MACAU. Hong Kong: Art Map Co., Ltd. 2015: 6 (44), P30. 